\title{
Females' Attitudes Toward Mental Illness: A Sample From Rural Istanbul, Turkey
}

\author{
Kamer Gur, ${ }^{1, *}$ and Leyla Kucuk ${ }^{2}$ \\ ${ }^{1}$ Department of Community Health Nursing, Faculty of Health Science, Marmara University, Istanbul, Turkey \\ ${ }^{2}$ Department of Mental Health and Psychiatric Nursing, Florence Nightingale Nursing Faculty, Istanbul University, Istanbul, Turkey \\ "Corresponding author: Kamer Gur, Department of Community Health Nursing, Faculty of Health Science, Marmara University, Istanbul, Turkey. Tel: +90-5336519027, Fax: \\ +90-2164183773, E-mail: kamergur@gmail.com
}

Received 2014 July 31; Revised 2014 September 05; Accepted 2014 September 28.

\begin{abstract}
Background: The beliefs, attitudes and behaviors of the society toward mentally ill patients may prevent these people from seeking help and accessing a successful treatment.

Objectives: The current study aimed to investigate mental illness among Turkish females residing in rural areas and their attitudes toward mental illness.

Patients and Methods: The current study was inferential cross-sectional. The population of this study consisted of 1000 households registered at the primary healthcare centre in Ademyavuz area who met the study inclusion criteria. The sample size was 387 females. Using the simple random sample selection method, certain females living in these households were included in the study. The socioeconomic status of the population in this region is low and middle-class. The adult population of the region is 10,960. Females comprise $39.8 \%$ of Ademyavuz population. The prevalence of mental illness in the district is unknown. Data were collected by faceto-face interviews using a researcher made questionnaire and the opinions about mental illness scale (OMI) in autumn 2008. The interviews were conducted at the participants' houses and lasted for 20 -30 minutes. The females gave their informed consent and were assured that their information would be treated as strictly confidential.

Results: The females in the rural research area had negative attitudes and stigmas about mental illness. The subject of the current study exhibited a total mean score of $155.6 \pm 24.5$ in terms of their attitudes toward mental illness. Mean scores in the unsophisticated benevolence sub-scale were $42.5 \pm 8.2,34.2 \pm 7.9$ in the authoritarianism sub-scale, $25.5 \pm 6.3$ in the mental illness ideology sub-scale, $34.0 \pm 7.4$ in the social restrictiveness sub-scale, and $20.0 \pm 6.0$ for the interpersonal etiology sub-scale. The current study found that individuals exhibited more positive attitudes towards mental illnesses as they got older $\left({ }^{\mathrm{Kvx} 2}=19.42 ; \mathrm{P}<0.0001\right)$, married people exhibited a more positive attitude towards mental illnesses than singles $\operatorname{did}\left(\mathrm{Kvx}^{2}=19.42 ; \mathrm{P}<0.0001\right)$, those who considered themselves to have a good economic status exhibited a more negative attitude towards mental illnesses compared to the ones who thought their economic status as poor or average $\left(\mathrm{Kvx}^{2}=5.11 ; \mathrm{P}=0.024\right)$.

Conclusions: Nurses have an important role in creating and maintaining a mentally healthy society. It is advisable to provide the public with training and consultancy services within the context of primary healthcare services, especially during home visits to change the negative attitudes of individuals against the mentally ill and prevent approaches that promote social isolation and denouncement.
\end{abstract}

Keywords: Mental Illness, Mental Disorders, Females, Rural, Nurse

\section{Background}

The ability of people with mental illness to resume their place in society and return to their former functions is associated with the general attitude of society toward mental illness. On the other hand, it is known that today the mentally ill are still approached with negative attitudes and rejection in all segments of the population. These attitudes are widespread in the community. It can be also observed that people feel the need to keep distance and avoid personal contact with the mentally ill and there is a tendency to cut off social contact with persons who have been diagnosed as mentally ill (1-3).

Stigma (branding) literally means scar, stain, or mark. Stigma is considered as a mark of disgrace or discredit, indicating the presence of an embarrassing situation for a person or a group of people. This perception results in many negative characteristics being attributed to such people and their possible exclusion from society (4).

Since individuals with mental illnesses are characterized as dangerous, offensive and aggressive, people tend to be afraid of them and blame them for their illnesses. Therefore, individuals with mental disorders may face segregation and isolation. The extent of social rejection impairs

Copyright (c) 2016, Iranian Red Crescent Medical Journal. This is an open-access article distributed under the terms of the Creative Commons Attribution-NonCommercial 4.0 International License (http://creativecommons.org/licenses/by-nc/4.0/) which permits copy and redistribute the material just in noncommercial usages, provided the original work is properly cited. 
the general health of individuals (5).

Parallel to the latest developments in the field of psychiatry, psychiatric disorders are more easily diagnosed but many people still tend to be unaware of the effective treatment options available for chronic or severe psychiatric illnesses. The stigma and tendency in society to ignore the mentally ill can be barriers to an individual's reaching out for help and accessing successful therapies. In other words, reducing stigmatization in society may play an important role to enable people to access effective treatment opportunities (6).

The mental health profile project for Turkey provides information on the incidence of mental illness in Turkey. This project reports that $18 \%$ of the Turkish population suffers from some kind of mental illness over their life (7). In terms of lessening the burden of individuals with mental illness and their caregivers, it is important to understand prevalent attitudes in society toward mental illness. In Turkish culture, particularly in rural areas, females take on the direct responsibility to look after the sick. The traditional role of females in society includes the roles of being a wife, mother, sister and child. From time immemorial, females are assigned the task of caring for babies, children and the elderly (8). The division of labor between males and females, the expectations from both genders, as well as social rights, responsibilities and cultural beliefs related to gender behavior may have an effect on health (9). Because of females' active role in both caregiving and motherhood, as role models for upcoming generations, their thoughts, attitudes and behavior are of great importance. In order to achieve improvements in health behavior among the population, the cultural factors that have an impact on health behavior should be explored $(10,11)$. An individual's beliefs, attitudes and behavior regarding health, experiences with treatment in the past, in short, a person's health culture all play a vital role in developing health habits, and preventing and treating diseases (12).

\section{Objectives}

The current study aimed to investigate mental illness among Turkish females residing in rural areas and their opinions toward mental illness.

\section{Patients and Methods}

\subsection{Research Type and Sample}

It was an inferential cross-sectional study. Study inclusion criteria were identified as follows: Ademyavuz neighbourhood residence, being registered at one of the primary healthcare centres in this area, age above 18 and being female; the people who did not meet these criteria were excluded from the study. There were 1000 households in the area that met the study inclusion criteria. The sample size was calculated by using the known formula. In this calculation, type I error was identified as 0.05 and type II as 0.10 . The sample size was calculated as 278 females. On account of missing data that can be encountered in the process of research and other shortcomings that may occur, it was decided to include 417 females in the sample. Onethousand households were listed as per their telephone numbers and lots were drawn until the sample size was completed. However, the study was conducted with the participation of 387 females. The participation rate in the study was $38.7 \%$. Nurses called the females at their homes and explained the nature of the research. Appointments were then set up with the females who consented to participate in the study and visits were made to their homes on an agreed date.

\subsection{Place and Time}

Data for the study were collected in autumn 2010. The people living in this region are of a low and middle socioeconomic status. The adult population in the region of Ademyavuz is 10,960 , of which $39.8 \%$ consisted of females. The prevalence of mental illness is unknown in this district.

\subsection{Data Collection Method}

Data were collected by 4 th year public health nursing interns in face-to-face interviews conducted with the respondents during visits made to their homes. The duration of the interviews was 20 - 30 minutes. The students who were interns were provided with a guide explaining the purpose of the study and the standards they would abide by in the data collection and recording process. It was mutually agreed that they would be faithful to this guide.

\subsection{Data Collection Instruments}

A questionnaire on demographic variables and the opinions on mental illness scale were used in the study.

\subsection{Socio-Demographic Questionnaire}

This questionnaire was developed by the researchers to collect data on the females' personal characteristics and consisted of 15 questions. A pilot administration was performed before the study and the statements that were not understood were corrected. 


\subsection{The Opinions About Mental Illness Scale}

The OMI scale developed by Cohen and Struening was used to measure attitudes toward mentally ill people and their personal characteristics, and toward mental illness, its etiology, and treatment.

The original OMI scale consisted of 51 items organized into five factorially-derived subscales: authoritarianism (OMI-A) (view of mentally ill as an inferior class requiring coercive handling), unsophisticated benevolence (OMIUB),(kindly, paternalistic view toward patients originating from religion and humanism rather than science), mental illness ideology (OMI-MII), (medical model adapted to psychiatric problems focusing on individual maladaptation and illness), social restrictiveness (OMI-SR), (the belief that mental patients are a threat to society and family and their functioning should be restricted), and interpersonal etiology (OMI-IE) (mental illness arises from interpersonal experience). Using a six-point Likert-type scale with response alternatives ranging from "Strongly disagree" to "Strongly agree," items were organized into five factorially-derived subscales: internal consistency reliability with values ranging from .65 to .80 . The total possible minimum score on the scale is 51 ; maximum score is 306.

\subsubsection{Scale Assessment}

The higher the scores, the more negative are the opinions of the individuals on this issue $(13,14)$. Arikan developed the Turkish adaptation of the scale (15) Cronbach's alpha value for this study was.82.

\subsection{Ethical Aspects}

On the days that the data were collected, the individuals at home were informed about the study and the study was completed with those who voluntarily agreed to participate. The females gave their informed consent and were assured that the information would be treated as strictly confidential.

\subsection{Statistical Analysis}

Data were analyzed using SPSS version 16. Descriptive statistics (frequency distribution percentage, median and interquartile range (IQR) were carried out to describe demographic data. Nonparametric tests were used since the data were not in line with the normal distribution. The data were evaluated in frequencies and with the MannWhitney $U$ and Kruskal-Wallis tests to evaluate the distribution normality of the OMI data, the Mann-Whitney U and Kruskal-Wallis tests were used to assess the relationship between overall OMI and the independent variables. A P value of less than 0.05 was considered significant.

\section{Results}

The majority of the females participating in the study were in the age group 18 - 28 (n: 192, 49.6\%), had only primary education (n: $128,33 \%$ ), were housewives (n: 173 , $44.7 \%$ ), married ( $\mathrm{n}: 249,64 \%$ ), reported their own economic status as average (n: $245,63.1 \%)$, were members of a nuclear family (n: 255, 66\%). Again, the majority of the subjects consisted of females who had no current psychiatric conditions requiring treatment ( $\mathrm{n}: 356,91.5 \%)$, no psychiatric history (n:348, 89.5\%), no mental problems within the family (n: 331, 85.6\%), no family members they were responsible to care for (n: $367,94.8 \%$ ) and no diagnosed mental disorders among their relatives/neighbors (n: 294, 75.6\%). Mean scores were $155.6 \pm 24.5$. Mean scores in the unsophisticated benevolence sub-scale were $42.5 \pm 8.2,34.2 \pm$ 7.9 in the authoritarianism sub-scale, $25.5 \pm 6.3$ in the mental illness ideology sub-scale, $34.0 \pm 7.4$ in the social restrictiveness sub-scale, and $20.0 \pm 6.0$ for the interpersonal etiology sub-scale (Figure 1). In terms of the individuals' ages and level of education, there were pronounced significant differences in the sub-factors outside the mental illness ideology and interpersonal etiology $\left[\left(\mathrm{Kvx}^{2}=14.41 ; \mathrm{P}\right.\right.$ = 0.002), $\left.\left.\left(\mathrm{Kvx}^{2}=15.53 ; \mathrm{P}=0.001\right), \mathrm{Kvx}^{2}=2.0 ; \mathrm{P}<0.000\right)\right]$; $\left[\left(\mathrm{Kvx}^{2}=11.4 ; \mathrm{P}=0.022\right),\left(\mathrm{Kvx}^{2}=15.7 ; \mathrm{P}=0.003\right),\left(\mathrm{Kvx}^{2}=15.7 ; \mathrm{P}\right.\right.$ $=0.003]$.

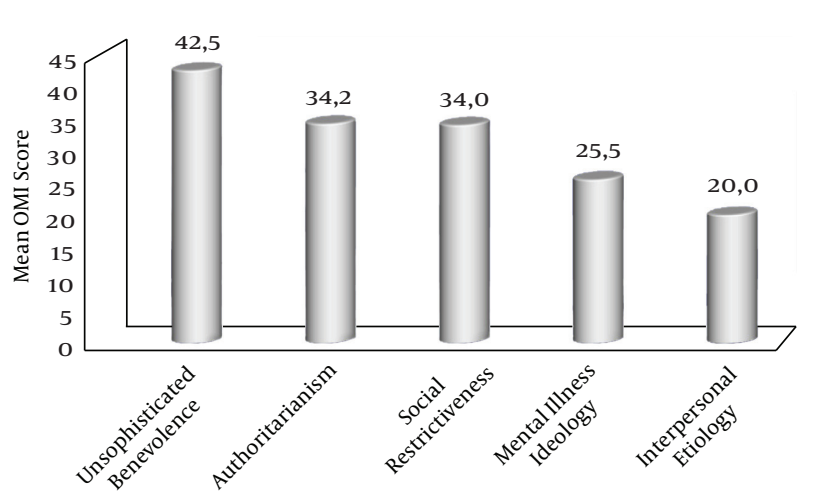

Figure 1. Mean Opinions About Mental Illness Scores of the Individuals by SubFactors of the Scale

In terms of social status, and family type, there were significant differences between the mean scores in the subfactors outside the mental illness ideology. [ $Z=3.78$; $P<$ $0.000),(Z=2.94 ; P=0.003),(Z=4.213 ; P<0.0001),(Z=2.66$; $\mathrm{P}=0.02)] ;[(\mathrm{Z}: 4.51 ; \mathrm{P}<0.0001),(\mathrm{Z}=2.89 ; \mathrm{P}=0.04),(\mathrm{Z}=3.82$; $\mathrm{P}<0.0001)(\mathrm{Z}=3.82 ; \mathrm{P}=0.00),(\mathrm{Z}=2.17 ; \mathrm{P}=0.029)]($ Table 1$)$.

In terms of economic status, there were significant differences among the mean scores in the sub-factors of authoritarianism and social restrictiveness $\left[\left(\mathrm{Kvx}^{2}: 4.86\right.\right.$; $\mathrm{P}$ : 
Table 1. Distribution of OMI/Sub-Factor Scores by Demographic Variables ${ }^{\mathrm{a}, \mathrm{b}}$

\begin{tabular}{|c|c|c|c|c|c|c|}
\hline & OMI-A & OMI-UB & OMI-MII & OMI-SR & OMI-IE & Total OMI \\
\hline \multicolumn{7}{|l|}{ Age } \\
\hline $18-28(n=192)$ & $35(31-40)$ & $43(38-49)$ & $26(23-29)$ & $36(31-40)$ & $20(16-25)$ & $162(146-174)$ \\
\hline $29-39(n=102)$ & $33(27-38)$ & $42(37-46)$ & $25(21-28)$ & $32(28-37)$ & $19(16-23)$ & $153(136-170)$ \\
\hline $40-49(n=47)$ & $34(29-37)$ & $43(37-47)$ & $24(21-28)$ & $33(30-38)$ & $18(15-22)$ & $152(138-164)$ \\
\hline 50 and $(n=46)$ & $31(26-36)$ & $39(34-45)$ & $25(21-27)$ & $31(26-35)$ & $19(16-22)$ & $149(126-162)$ \\
\hline $\mathrm{Kvx}^{2} / \mathrm{P}$ & $14.41 / 0.002$ & $15.53 / .001$ & $7.54 / 0.065$ & $26.0 /<0.0001$ & $7.57 / 0.065$ & $19.42 /<0.0001$ \\
\hline \multicolumn{7}{|l|}{ Educational level } \\
\hline Illiterate $(n=17)$ & $30(24-36)$ & $37(32-43)$ & $24(20-26)$ & $31(25-36)$ & $18(14-23)$ & $151(120-164)$ \\
\hline Literate $(\mathrm{n}=30)$ & $29(23-34)$ & $39(32-44)$ & $25(20-28)$ & $27(24-34$ & $17(13-21)$ & $146(119-160)$ \\
\hline Elementary school $(\mathrm{n}=128)$ & $33(28-36)$ & $41(37-46)$ & $25(22-28)$ & $33(28-36)$ & $19(16-23)$ & $151(138-168)$ \\
\hline Middle school $(n=47)$ & $33(28-39)$ & $43(39-48)$ & $25(22-30)$ & $34(31-37)$ & $19(16-22)$ & $154(143-168)$ \\
\hline High school $(n=62)$ & $34(30-39)$ & $43(38-48)$ & $25(22-28)$ & $35(30-38)$ & $20(16-24)$ & $158(145-174)$ \\
\hline University $(\mathrm{n}=103$ ) & $38(32-42)$ & $45(40-49)$ & $26(22-29)$ & $38(33-41)$ & $21(18-26)$ & $165(155-181)$ \\
\hline $\mathrm{Kvx}^{2} / \mathrm{P}$ & $11.4 / 0.022$ & 15.70 .003 & $2.03 / 0.730$ & $15.7 / 0.003$ & $5.47 / 0.242$ & $11.82 \mid<0.0001$ \\
\hline \multicolumn{7}{|l|}{ Social status } \\
\hline Single $(n=138)$ & $36(30-42)$ & $44(38-49)$ & $25(22-28)$ & $36(30-40)$ & $20(17-25)$ & $163(147-175)$ \\
\hline Married $(n=249)$ & $33(28-37)$ & $42(37-46)$ & $25(21-28)$ & $33(29-37)$ & $19(16-23)$ & $153(138-168)$ \\
\hline $\mathrm{Z} / \mathrm{P}$ & $3.78 /<0.0001$ & $2.94 / 0.003$ & $1.03 / 0.300$ & $4.13 /<0.0001$ & $2.66 / 0.02$ & $3.91 /<0.0001$ \\
\hline \multicolumn{7}{|l|}{ Economic status } \\
\hline Poor $(n=65)$ & $32(27-36)$ & $41(36-45)$ & $25(22-28)$ & $32(26-36)$ & $18(16-21)$ & $151(133-164)$ \\
\hline Average $(n=245)$ & $34(29-40)$ & $42(37-48)$ & $25(21-28)$ & $34(30-38)$ & $20(16-24)$ & $158(143-172)$ \\
\hline Good $(n=77)$ & $36(30-39)$ & $45(40-48)$ & $26(22-29)$ & $35(31-39)$ & $21(12-24)$ & $163(147-175)$ \\
\hline $\mathrm{Kvx}^{2} / \mathrm{P}$ & $4.86 / .027$ & $3.04 / 0.081$ & $0.28 / 0.867$ & $5.56 / .015$ & $2.67 / 0.116$ & $5.11 / 0.024$ \\
\hline \multicolumn{7}{|l|}{ Family type } \\
\hline Nuclear $(\mathrm{n}=255)$ & $36(30-41)$ & $43(38-48)$ & $25(22-29)$ & $35(30-39)$ & $20(16-24)$ & $161(145-174)$ \\
\hline Expanded $(n=132)$ & $32(27-36)$ & $41(37-45)$ & $25(21-28)$ & $31(27-37)$ & $19(16-23)$ & $148(138-164)$ \\
\hline $\mathrm{Z} / \mathrm{P}$ & $4.51 \mid<0.0001$ & $2.89 / 0.004$ & $1.04 / 0.296$ & $3.82 \mid<0.0001$ & $2.17 / .029$ & $4.17 \mid<0.0001$ \\
\hline
\end{tabular}

${ }^{\mathrm{a}} \mathrm{N}=387$.

${ }^{\mathrm{b}}$ Values are expressed as median (IQR).

0.027), $\left.\left(\mathrm{Kvx}^{2}=5.56 ; \mathrm{P}=0.015\right)\right]$. Significant differences were found between the OMI total scores and the mean scores in the authoritarianism, unsophisticated benevolence and social restrictiveness sub-factors for individuals who had or did not have people in the family with mental problems. $[(\mathrm{Z}=3.13 ; \mathrm{P}=0.02),(\mathrm{Z}=2.86 ; \mathrm{P}=0.04),(\mathrm{Z}=2.64 ; \mathrm{P}=0.05),(\mathrm{Z}$ $=2.63 ; \mathrm{P}=0.02)]$ (Table 2).

\section{Discussion}

This section discusses the variables that influence the attitudes toward mental illness of females living in a ru- ral neighborhood of Istanbul, Turkey. The opinions and attitudes regarding patients with mental illness are multidimensional and for this reason should be identified in terms of multi-factors. The females in the study exhibited a total mean score of $155.6 \pm 24.5$ in terms of their attitudes toward mental illness. The study data showed that females living in the rural parts of Istanbul were under the influence of stigmatization in their attitudes toward mental illness. However, the scores obtained in the unsophisticated benevolence sub-factor, reflecting a kindly, paternalistic view toward patients whose origins derive from religion and humanism rather than science, were higher than 


\begin{tabular}{|c|c|c|c|c|c|c|}
\hline & OMI-A & OMI-UB & OMI-MII & OMI-SR & OMI-IE & Total OMI \\
\hline \multicolumn{7}{|l|}{ Psychiatric History } \\
\hline Yes $(n=39)$ & $35(30-40)$ & $43(40-47)$ & $26(22-28)$ & $34(30-40)$ & $20(15-24)$ & $162(143-176)$ \\
\hline No $(\mathrm{n}=348)$ & $34(29-39)$ & $43(40-47)$ & $25(22-28)$ & $34(29-38)$ & $19(16-23)$ & $157(142-171)$ \\
\hline $\mathrm{Z} / \mathrm{P}$ & $0.505 / 0.613$ & $0.966 / 0.334$ & $0.088 / 0.930$ & $0.812 / 0.417$ & $772 / 0.440$ & $0.907 / 0.364$ \\
\hline \multicolumn{7}{|c|}{ Mental Illness in the Family } \\
\hline Yes $(n=56)$ & $36(31-42)$ & $45(42-48)$ & $25(22-28)$ & $36(33-41)$ & $21(17-24)$ & $165(153-176)$ \\
\hline No $(n=331)$ & $33(29-38)$ & $42(37-47)$ & $25(22-29)$ & $34(29-38)$ & $19(16-23)$ & $156(141-170)$ \\
\hline $\mathrm{Z} / \mathrm{P}$ & $2.86 / 0.004$ & $2.64 / 0.05$ & $0.061 / 0.951$ & $2.63 / 0.02$ & $2.03 / 0.42$ & $3.13 / 0.02$ \\
\hline
\end{tabular}

the mean scores in the other sub-factors. This shows that even though there is stigmatization regarding mental illness, females are more dominated by a feeling of benevolence toward the mentally ill. In second and third place is the sub-factor authoritarianism, which reflects a condescending view that the mentally ill are different from normal people, and the sub-factor social restrictiveness, which is a manifestation of the view that mentally ill individuals need to be restricted during their hospitalization and later as well so that society can be protected from their actions and from their posing a threat to the community. Fourth is the view based on mental illness ideology that believes mental illness is just like any other disease and therefore should not be looked at as a different category of illness. The lowest mean score was obtained in the interpersonal etiology sub-factor. This factor is based on the belief that mental illness stems from dysfunctional relations between parents and child during childhood.

The studies that examined people's attitudes toward illnesses in Turkey reported that, especially in mental diseases such as schizophrenia, negative attitudes prevail and people with the sickness are rejected and social contact is avoided $(7,16)$. Particularly in rural areas, it is reported that attitudes may be even more negative and rejection may be even more rampant (16). According to Ozmen et al. there is more stigmatization associated with mental illnesses such as depression in Turkey than in Europe or north America (17).

Different demographic variables may affect stigmatization. The elderly, those with a lower level of education, and people that are at a lower socioeconomic level, are less tolerant of mental illnesses. Studies report that patients living in rural areas are more likely to be rejected and stigmatized by society and that this is an important issue to consider. This is perhaps the reason that the mentally ill may choose to seek alternative methods of treatment. It is also known that especially individuals living in rural areas that are of lower socioeconomic status do not seek psychiatric help for either themselves or their relatives. This avoidance seriously affects the ability of people to receive psychiatric treatment (18-20).

The literature refers to age as having both a positive and a negative effect on attitudes toward mental illness. This study found that individuals exhibit more positive attitudes towards mental illnesses as they get older $\left(\mathrm{Kvx}^{2}\right.$ $=19.42 ; \mathrm{P}<0.0001)$. The evidence in the research that showed the older the participants, the more positive an attitude they assumed toward mental illness can be related to the fact that older people have more experience and can therefore develop a positive viewpoint over time. On the other hand, in another study, older participants stated that patients with depression were aggressive and should not be allowed to freely circulate in the community (21). The results of a study by Taskin et al. indicated that demographic variables such as age and gender did not have a significant effect on opinions (16).

In this study, it was found that the more educated participants were, the more negative were their attitudes toward mental illness. It might be based on this finding that the more educated people are, the more they will have knowledge of the literature on mental illnesses and this would lead them to support the widespread belief that the mentally ill differ from normal people. Therefore, there would be a tendency in this case to protect the community and particularly one's own family from the supposed threat by restricting the actions of the mentally ill. According to Bhugra and Jorm et al. people with higher educational backgrounds do not wish to be in close contact with schizophrenic patients and as the educational level increases, a more negative attitude seems to develop (22, 
23). On the other hand, there are studies that defend the opposite belief that people are more positive about mental illness when they are more educated $(8,24)$.

In the current study, those who regard their economic status as good exhibited a more negative attitude towards mental illnesses compared to those who thought their economic status was poor or average $\left(\mathrm{Kvx}^{2}=5.11 ; \mathrm{P}=0.024\right)$. However, de Toledo Piza Peluso and Blay reported that as economic status improves, a more positive attitude is shown toward mental illness (24). According to Ozmen et al. however, socioeconomic levels had no influence on the social distance kept between the study respondents and individuals suffering from mental illness (21). When the effects of socioeconomic levels on stigmatization attitudes are examined, it is observed that people from a higher socioeconomic background report that they are more knowledgeable about mental illness and can be more tolerant of people with mental illness (25). The present study indicated, however, opposite results. This dissimilarity may stem from cultural differences in society. It is unfortunate that in Turkish society, a person's economic status determines social class.

Married people exhibited a more positive attitude towards mental illnesses than singles did $(\mathrm{Z}=3.91 ; \mathrm{P}<$ 0.0001). In the light of this result, it might be said that single people were of the opinion that people with mental illness are different from the normal population, of less value, and that their actions should be restricted to protect the community and families. Ozmen et al. (21), however, reported that marital status had no influence on the social distance kept between respondents and individuals suffering from depression. Being married brings results in the spontaneous tendency to build relations with other people and eliminates the apprehensions that may accompany being single. Comparatively, since single people may display more of a need for security, which may influence them in their thoughts about restricting the actions of the mentally ill. Individuals living in nuclear families show a more negative attitude towards mental illnesses than those who live in extended families $(\mathrm{t}=4.08 ; \mathrm{P}=0.000)$. In other words, it may be said that people in a nuclear family are more likely than those in an extended family to perceive the mentally ill as different, lower in value, and in need of being restricted, and to believe that mental illness is the result of dysfunctional relations between parents and child, especially in childhood.

The current study indicated that people with mental illness in the family had higher scores in the sub-factors of authoritarianism, unsophisticated benevolence, social restrictiveness and in total OMI mean scores, compared to those without mental illness in the family. While in some cases, experiences related to mental illness can provide strength and a more positive attitude, in other cases, mental illness is met with negativity and rejection. In particular, the physical and emotional burden of mental illness may cause relatives of a patient to feel guilty or lead to the family as well as the patient to be stigmatized and isolated by society (19). Arkar and Eker assert that having a direct experience leads to adopting a more realistic attitude and such an attitude is not likely to change. When a danger is sensed, attitudes shift toward the negative; people feel the need to place distance between themselves and the mentally ill (26). According to Dyduch and Grzywa, person's profession, frequency of contact with mentally ill persons, personal experience, level of mental health literacy, education level, culture-related factors, overall value orientation, age and gender are the most relevant factors which influence the perfection of the people suffering from mental disorders (27). The findings of the current study are similar to what is reported in the literature.

The current study has an important advantage because it was conducted by face-to-face interviews and not as a public study. Since data were collected in the comfort of people's homes, the respondents may have felt more secure. The study is limited however to the sampling and may not be generalized.

\subsection{Conclusions}

The females living in the rural area in which this study was conducted had negative attitudes toward mental illness and were under the influence of stigmatization. While the young and married had positive opinions, being at a higher economic status, having a higher educational background, and being in a nuclear family were factors that caused a more negative attitude toward mental illness.

\subsection{The Strengths of This Study}

First and foremost, it was conducted in the home setting where individuals could express themselves more comfortably and data were collected by nurses working in the area in home visits. Furthermore, the results of this study will add value to the literature in this field since no studies on this subject were found in the national literature. As for the weakness of the study, it could be the small sample size.

\subsection{Recommendations}

Negative opinions indiscriminately overemphasize social handicaps that can accompany mental disorders. They contribute to the social isolation, distress and difficulties in employment. Knowledge about mental illnesses is an important tool to improve attitudes toward the mentally 
ill. Females have an important role in creating and maintaining a mentally healthy society. In order to contribute to raising the quality of mental health in Turkish society and increasing the effectiveness of public mental health services, specially trained health professionals need to reach out to the public. The social restrictiveness that particularly females who find themselves in the position of caregivers place upon themselves and their patients is an important issue. It is firstly necessary to determine the symptoms of mental illness in females and establish through qualitative research what their beliefs are regarding mental illness and to plan programs to improve their attitudes. Public education is of vital importance. Misunderstandings, misbeliefs, prejudices and the myths in general need to be eradicated.

Public health nurses have an important role in creating and maintaining a mentally healthy society. It is advisable to provide the public with training and consultancy services within the context of primary healthcare services, especially during home visits, in order to change negative attitudes of individuals against mentally ill people and to prevent approaches that cause social isolation and denouncement.

\section{Acknowledgments}

Authors thank the 4th year students who voluntarily helped this research project during their 2010 fall semester internship program and all others who contributed and participated in the study.

\section{Footnote}

Authors' Contribution: Study concept and design, Kamer Gur and Leyla Kucuk; analysis and interpretation of data, Kamer Gur; drafting of the manuscript, Kamer Gur and Leyla Kucuk; critical revision of the manuscript for important intellectual content, Kamer Gur and Leyla Kucuk; statistical analysis, Kamer Gur.

\section{References}

1. Arkar H. Social rejection of mentally ill [in Turkish]. Dusunen Adam. 1991;4:6-9.

2. Angermeyer MC, Matschinger H. The stigma of mental illness: effects of labelling on public attitudes towards people with mental disorder. Acta Psychiatr Scand. 2003;108(4):304-9. [PubMed: 12956832].

3. Copeland D, Diane V. In: Family Health Care Nursing Theory Practice Research Book. 4th ed. Kaakinen JR, Coehlo DP, Gedaly-Duff V, Hanson S, editors. Philadelphia: F. A. Davis Company; 2010. Family mental health nursing.

4. Gary FA. Stigma: barrier to mental health care among ethnic minorities. Issues Ment Health Nurs. 2005;26(10):979-99. doi: 10.1080/01612840500280638. [PubMed: 16283995].
5. Emrich K, Thompson TC, Moore G. Positive attitude. An essential element for effective care of people with mental illnesses. J Psychosoc Nurs Ment Health Serv. 2003;41(5):18-25. [PubMed: 12743963].

6. Hugo CJ, Boshoff DE, Traut A, Zungu-Dirwayi N, Stein DJ. Community attitudes toward and knowledge of mental illness in South Africa. Soc Psychiatry Psychiatr Epidemiol. 2003;38(12):715-9. doi: 10.1007/s00127003-0695-3. [PubMed: 14689176].

7. Saglik Bakanligi TC. Ulusal Eylem Plani 2003. [cited 2014 Sep 11]. Available from: http://www.saglik.gov.tr/TR/dosya/1-73168/h/ulusalruh-sagligi-eylem-plani.pdf.

8. Berman A, Snyder SS, Kozier B, Erbs G. Fundamentals of nursing concepts, process and practice. 8th ed. ; 2008. pp. 5-13.

9. Bolsoy N, Sevil U. Interaction of Health, Sickness and Culture [in Turkish]. Ataturk Universitesi Hemşirelik Yuksekokulu Dergisi. 2006;9:78-87.

10. Williamson $M$, Harrison L. Providing culturally appropriate care: a literature review. Int J Nurs Stud. 2010;47(6):761-9. doi: 10.1016/j.ijnurstu.2009.12.012. [PubMed: 20138275].

11. Tanrıverdi G, Sevig U. Nursing across cultures. 1th ed. Istanbul: Oray Basım; 2012.

12. Kuguoglu S. In: Care of Patients with Internal Diseases and Surgical Patients [in Turkish]. Karadakovan A, Eti Aslan F, editors. Adana: Nobel Kitabevi; 2011. Transkulturel Hemsirelik.

13. Cohen J, Struening EL. Opinions about mental illness in the personnel of two large mental hospitals. J Abnorm Soc Psychol. 1962;64:349-60. [PubMed: 13880267].

14. Struening EL, Cohen J. Factorial invariance and other psychometric characteristics of five opinions about mental illness factors. Educ Psychol Meas. 1963;23(2):289-98. doi: 10.1177/001316446302300206.

15. Bostanci N. Investigating psychiatric and non-psychiatric nurses' opinions toward persons with mental disorders. Istanbul: Istanbul University; 2000.

16. Taskin EO, Sen FS, Aydemir O, Demet MM, Ozmen E, Icelli I. Public attitudes to schizophrenia in rural Turkey. Soc Psychiatry Psychiatr Epidemiol. 2003;38(10):586-92. doi:10.1007/s00127-003-0655-y. [PubMed: 14564386].

17. Ozmen E, Ogel K, Aker T, Sagduyu A, Tamar D, Boratav C. Public attitudes to depression in urban Turkey - the influence of perceptions and causal attributions on social distance towards individuals suffering from depression. Soc Psychiatry Psychiatr Epidemiol. 2004;39(12):1010-6. doi:10.1007/s00127-004-0843-4. [PubMed: 15583910].

18. Loganathan S, Murthy SR. Experiences of stigma and discrimination endured by people suffering from schizophrenia. Indian J Psychiatry. 2008;50(1):39-46. doi: 10.4103/0019-5545.39758. [PubMed: 19771306].

19. Taskın O. Stigma Ruhsal Hastalıklara Yönelik Tutumlar ve Damgalanma. Izmir: Meta Basım Yayın; 2007. pp. 80-9.Factors influencing attitudes and stigmas regarding mental illness [in Turkish].

20. Ozmen E, Ozmen D, Taskin EO, Demet MM. In: Public Opinion Research Focus. Petrieff LO, Miller RV, editors. New York: Nova Publishers; 2008. pp. 135-48.Influence of psychopathology type on attitudes toward psychiatric disorders.

21. Ozmen E, Ogel K, Boratav C, Sagduyu A, Aker T, Tamar D. The knowledge and attitudes of the public towards depression: an Istanbul population sample [in Turkish]. Turk Psikiyatri Derg. 2003;14(2):89-100. [PubMed: 12844275].

22. Bhugra D. Attitudes towards mental illness. A review of the literature. Acta Psychiatr Scand. 1989;80(1):1-12. [PubMed: 2669442].

23. Jorm AF, Korten AE, Jacomb PA, Rodgers B, Pollitt P, Christensen H, et al. Helpfulness of interventions for mental disorders: beliefs of health professionals compared with the general public. Br J Psychiatry. 1997;171:233-7. [PubMed: 9337975].

24. de Toledo Piza Peluso E, Blay SL. Community perception of mental disorders - a systematic review of Latin American and Caribbean studies. Soc Psychiatry Psychiatr Epidemiol. 2004;39(12):955-61. doi: 10.1007/s00127-004-0820-y. [PubMed: 15583902]. 
25. Ersoy MA, Varan A. Reliability and validity of the Turkish version of the internalized stigma of mental illness scale [in Turkish]. Turk Psikiyatri Derg. 2007;18(2):163-71. [PubMed: 17566882].

26. Arkar H, Eker D. Influence of having a hospitalized mentally ill member in the family on attitudes toward mental patients in Turkey. Soc
Psychiatry Psychiatr Epidemiol. 1992;27(3):151-5. [PubMed: 1621141]. 27. Dyduch A, Grzywa A. Stigma and related factors basing on mental illness stigma [in Turkish]. Pol Merkur Lekarski. 2009;26(153):263-7. [PubMed: 19388546]. 